\title{
Model Study of Alkali-Activated Waste Binder for Soil Stabilization
}

\author{
Shahram Pourakbar ${ }^{1} \cdot$ Bujang B. K. Huat ${ }^{1} \cdot$ Afshin Asadi $^{1}$. \\ Mohammad Hamed Fasihnikoutalab ${ }^{1}$
}

Received: 29 June 2016/ Accepted: 22 October 2016/Published online: 5 November 2016

(C) Springer International Publishing Switzerland 2016

\begin{abstract}
This study assesses the laboratory investigation to evaluate the feasibility of using alkaline activation technique for engineering improvement of soils. The originality of this paper stems from the novel two-stage approach. The first stage investigates the effectiveness of locally available precursor in the alkaline activation process by focusing on soil strength improvement. As such, in presence of high alkali solutes (Na-based and Ka-based alkaline activators), palm oil fuel ash (POFA) was used as a precursor due to its amorphous nature and high silica-toalumina ratio. In the second stage of this study, geotechnical model procedure of interaction between a strip footing model and stabilized soil by column technique and the most effective percentage of POFA was performed. According to the test results, applying alkaline activators to soil induced low strengths of up to $159 \mathrm{kPa}$ after 7 days curing. When the POFA content used in alkaline activation increased from 0 to $15 \%$, the UCS values increased up to $226 \%$ after similar curing duration. This assertion reflects the fact that the addition of POFA enriched the reactive $\mathrm{Si}$ and $\mathrm{Al}$ in the matrix, which allowed stronger $\mathrm{Si}-\mathrm{O}-\mathrm{Si}$ and $\mathrm{Al}-\mathrm{O}-\mathrm{Si}$ bonds to form. Curing condition, type and quantity of the alkaline activators were also shown to have significant strengthening effects on the treated soil. In this respect, the use of moderate $10 \mathrm{M} \mathrm{NaOH}$ and $10 \mathrm{M} \mathrm{KOH}$ were found to be viable as the best concentration for strength improvement of investigated soil when economy and practicality were considered. In terms of using alkali-
\end{abstract}

Shahram Pourakbar

shahram.pourakbar@yahoo.com

1 Department of Civil Engineering, Faculty of Engineering, Universiti Putra Malaysia, 43400 Serdang,

Selangor Darul Ehsan, Malaysia activators, the use of the $\mathrm{NaOH}$ for soil treatment is beneficial in terms of lower cost, since the price of $\mathrm{KOH}$ solution is higher than that of the $\mathrm{NaOH}$ solution. Results of the second phase showed that a considerable settlement reduction up to $192 \%$ of treated columns by means of alkaline activation could be achieved.

Keywords Soil stabilization - Alkaline activation - Waste materials · Deep mixing method

\section{Introduction}

A variety of soil stabilization techniques have been applied to improve the bearing capacity of soft soil, such as granular and prefabricated vertical drains, vacuum consolidation, granular column reinforcement (sand compaction piles, vibrated stone columns), and stabilising techniques (deep mixing, pre-mixing and lightweight treated soil) [1, 2]. Of the soil stabilising techniques, the inclusion of treated soil columns using the deep soil mixing has been among the most popular, after it was initiated thirty years ago $[3,4]$.

In a broad perspective, deep stabilisation of soils is an in situ soil modification technique using a stabilizing agent to improve bearing capacity, reduce settlement, prevent shear deformation of soils, and treat contaminated soils [5-8]. According to the literature, this method has several advantages: (1) speed of construction, (2) strength calibration, (3) reliability, (4) variety of applications, and (5) effective use of resources $[6,9,10]$.

Due to their robustness and easy adoptability, calciumbased binders (i.e., cement and lime) were employed as stabilizing agents in this method to produce stronger and firmer ground namely soil-cement/lime columns [11, 12]. Although such traditional chemical binders can improve 
many engineering properties of soils, they have several shortcomings, especially when viewed from an environmental perspective.

In order to minimize these problems, the development of new soil binders with mechanical performance equal to or better than that of cement and other traditional calciumbased binders but lower environmental ill effect and processing costs seems to be of great interest. In this respect, recent years have seen great developments around the world regarding the development of a new type of high performance inorganic material: alkali-activated binders. Essentially, the synthesis of alkali-activated binders, which are formed by the reaction of any amorphous $\mathrm{Si}-\mathrm{Al}$ primary material, involves the dissolution of mineral aluminosilicates, hydrolysis of $\mathrm{Al}$ and $\mathrm{Si}$ components, and condensation of specific $\mathrm{Al}$ and $\mathrm{Si}$ species. After the initial and high-pH dissolution phase, a decrease of the alkalinity of the medium below 13.5 starts the poly-condensation process. This is the followed by the formation of a threedimensional, essentially amorphous, aluminosilicate gel. Throughout the development of reactions, the constitutive water is gradually consumed, originating a well-structured aluminium silicate hydrate (A-S-H) framework [13, 14].

The process of stabilization in alkali-activated binder and traditional calcium-based binders is vastly different, as they use totally different reaction pathways in order to attain structural integrity. Utilization of calcium-based binders depends on the presence of calcium silicate hydrate (C-S-H) and calcium aluminium hydrate (C-A-H) gels for matrix formation and strength $[15,16]$, whereas in alkali-activated binders, strong alkali solutions are needed to start the dissolution process and subsequent formation of A-S-H gel [17, 18].

Review of literature reveals that in limited attempts, geotechnical researchers investigated the effectiveness of the alkaline activation from various precursors such as metakaolin [19, 20], fly ash [21-23], and mixture of fly ash and blast furnace slag [24] for the purpose of soil stabilization. These studies were conducted by thoroughly mixing the above mentioned precursors with soft soils in the presence of sodium hydroxide and a silica-rich source (sodium silicate) as the alkaline activator. A significant body of these studies validate the proposition that the alkali-activated binder is a successful method of deep soil stabilisation.

Despite such positive findings, several issues were not well recognised, such as type and quantity of alkaline solute, use of precursor, and curing condition. Other than that, the current lack of adequate knowledge of the application of alkali-activated binder in deep mixing projects highlights the importance of laboratory study on stabilized soil columns with the aim of better understanding of their performance under compression.

Moreover, to derive the economic benefits of this promising method for the purpose of soil treatment, there is a high need to explore the locally available materials, especially the materials that contribute to the volume of waste. Framed by this context, among the possibilities of utilizing various by-products and natural prime materials in the process of alkaline activation, the use of palm oil fuel ash (POFA) deserves a special attention. POFA is a wellknown agricultural residue widely produced in large quantities in East Asian (Indonesia, Thailand, and Malaysia) and West African countries (Benin Republic, Ghana, and Nigeria) by the oil palm industry. From geotechnical and geoenvironmental points of view, utilizing such a locally available by-product along with alkali-activated binder would pave the way for other potential uses of low value by-products in this promising technique as efficient soil binders.

The first stage of this study aims to investigate a possibility of using a POFA based alkali activated binders (Kabased and Na-based activators solution) to stabilise a problematic soil based on compressive strength improvement. In this stage, the unconfined compressive strength (UCS) was used as a practical indicator to investigate the strength development.

In the following stage experiments were conducted the experimental tests by preparing and installing groups of columns with the most effective percentage of precursor (POFA) in presence of highly alkali solutes beneath a rigid steel plate to model the behaviour of foundation rest on a stabilized soil columns. Here, key aspects of the study are ultimate bearing capacity $\left(q_{\text {ult }}\right)$ of group of stabilized columns with different replacement area ratio.

\section{Experimental Investigation}

\section{Materials}

The physical properties and chemical composition of clayey soil used in this experiment are listed in Tables 1 and 2 , respectively. It is important to mention that, according to the Unified Soil Classification System ASTM D2487 [25], the original soil is classified as high-plasticity clay $(\mathrm{CH})$. Strength of this type of soil is often not enough to enable its use in earth works or foundation layers, and thus constitutes an ideal challenge.

Table 1 Physical and chemical characteristics of clayey soil

\begin{tabular}{lll}
\hline Basic soil property & Standard & Value \\
\hline Specific gravity $\left(G_{\mathrm{s}}\right)$ & BS 1377: part 2 & 2.6 \\
Liquid limit $(\%)$ & BS 1377: part 2 & 60 \\
Plastic limit (\%) & BS 1377: part 2 & 31 \\
Optimum water content $(\%)$ & BS 1377: part 4 & 32 \\
Maximum dry unit weight $\left(\mathrm{kN} / \mathrm{m}^{3}\right)$ & BS 1377: part 4 & 12.65 \\
\hline
\end{tabular}


Table 2 Chemical composition of natural soil and POFA (percentage)

\begin{tabular}{llll}
\hline Constituent $(\%)$ & Natural soil & Natural POFA & Treated POFA \\
\hline Silica $\left(\mathrm{SiO}_{2}\right)$ & 30.98 & 46.042 & 55.78 \\
Alumina $\left(\mathrm{Al}_{2} \mathrm{O}_{3}\right)$ & 18.35 & 19.391 & 17.29 \\
Iron oxide $\left(\mathrm{Fe}_{2} \mathrm{O}_{3}\right)$ & 12.8 & 6.10 & 4.17 \\
Calcium oxide $(\mathrm{CaO})$ & 0.2 & 13.874 & 11.93 \\
Potash $\left(\mathrm{K}_{2} \mathrm{O}\right)$ & 6.67 & 8.615 & 7.79 \\
Magnesia $(\mathrm{MgO})$ & 0.5 & - & - \\
Loss on ignition & - & 9.68 & 1.5 \\
\hline
\end{tabular}

The POFA (precursor) used in this study was collected from a factory in Johor in the southern state of Malaysia. From the chemical analyses of POFA (Table 2), this agricultural residue has high amounts of silica in amorphous phase. Thus, this by-product can be a suitable alternative for use in the alkaline activation system as a soil stabilizer. However, the limiting factors which may hinder the use of POFA in the alkaline activation process are its low reactivity with residual carbon as the major impurity and other trace elements such as $\mathrm{P}$ and $\mathrm{K}$.

To achieve a suitable chemical composition along with a favourable size and shape, the POFA was first subjected to a pre-treatment, which included calcination and grinding. After drying the POFA in an oven for $24 \mathrm{~h}$, at $105^{\circ} \mathrm{C}$, the In the next step, in order to remove any unburned carbon, the ground POFA was heated at $440{ }^{\circ} \mathrm{C}$ in an electric furnace, for about $1 \mathrm{~h}$. After the pre-treatment procedure, $\mathrm{X}$-ray fluorescence (XRF) spectrometry was used for elemental analysis (Table 2). The same pre-treatment process has recently been adopted by other researchers [26-30], whom reported the method to be effective in terms of increasing the specific surface and consequently, the reactivity of the POFA.

Sodium hydroxide $(\mathrm{NaOH})$ and potassium hydroxide $(\mathrm{KOH})$, containing $\mathrm{Na}^{+}$and $\mathrm{K}^{+}$alkaline cations, respectively, were selected as alkali-activators in the current study due to their well-known efficiency in alkaline activation process. Both reagents were supplied in pellet form by the company $\mathrm{R} \& \mathrm{M}$ Chemical, and were previously diluted in distilled water to achieve a pre-designed concentration.

\section{Laboratory Tests}

\section{Unconfined Compressive Strength}

Compressive strength $\left(q_{\mathrm{u}}\right)$ is defined as the compressive stress at which an unconfined cylindrical specimen of soil will fail in a simple compressive test. In addition, in this test method the unconfined compressive strength (UCS) is taken as the maximum load attained per unit area, or the load per unit area at $15 \%$ axial strain, whichever occurs first during the performance of a test. In this study, the UCS tests were conducted in accordance with Part 7:Clause 7 of the BS 1377 standard [31] and the results were accepted only if deviated less than $5 \%$ from the average.

The UCS tests defined as the stress corresponds to the peak stress condition. Stress values were measured at specified ages in three specimens for each mixture and all data points deviated less than $5 \%$ from the average.

As shown in Table 3, for the UCS tests, excluding a predesigned activator concentration (Na-based and $\mathrm{Ka}$ based alkali activators) to dry solid content, a total of 10 mixes were prepared using two activators, with and without varying POFA dosages (by dry mass of soil).

To prepare the samples, in the first step, different alkaline activators were dissolved in the solution at predetermined concentration. In this step, distilled water was used to dissolve activator pellets to avoid the effect of unknown contaminants in the mixing water. Since this reaction is highly exothermic and to avoid increasing the plasticity of the host soil, the alkaline solutes were prepared and cooled down for $24 \mathrm{~h}$ before being used in the mixture. Meanwhile, the needed amount of natural soil was air dried for $24 \mathrm{~h}$. In the next step, the required dosage of air dried soil was mixed by adding the cooled alkaline solution with the specified weights of POFA (percent by dry weight of soil) and extra distilled water until a uniform blend was produced. Note that the distilled water value used in the mixing procedure included both the water in the first and second steps to meet the optimum water content of host soil. Also, it should be mentioned that the dry unit weight value of $12.65 \mathrm{kN} / \mathrm{m}^{3}$ was adopted for all mixes.

The specimens were prepared directly after the aforementioned mixing procedure, by manual compaction, in a cylindrical mold with $50 \mathrm{~mm}$ in diameter and $100 \mathrm{~mm}$ high, using a $45 \mathrm{~mm}$ diameter steel rod to apply a static load in three similar layers. Since $\mathrm{NaOH}$ and $\mathrm{KOH}$ are strong bases, compacted specimens in the presence of such activators were not strong enough to be remoulded. Therefore, the cylinder samples were extruded with extreme caution. Immediately after extrusion, all specimens were tightly wrapped in polythene covers to avoid water loss and cured in a laboratory ambient environment under selected curing times (7, 14 and 28 days of curing) prior to testing.

Note that in an effort to investigate the role of the curing temperature on the improved strength of treated soil, soon after mixing process, a few cylinder specimens (6 mixes) were heated at $100{ }^{\circ} \mathrm{C}$ for around $1 \mathrm{~h}$ in an electric furnace. After heating, these specimens were closely wrapped in polythene covers to avoid water loss and cured in a laboratory ambient environment for 28 days. 
Table 3 The testing groups of samples

\begin{tabular}{|c|c|c|c|c|}
\hline Group & Mixture & Sample & Activator concentration (M) & Curing time (days) \\
\hline $\mathrm{S}$ group & $\mathrm{S}$ & Soil & 0 & - \\
\hline \multirow[t]{2}{*}{$\mathrm{N}-\mathrm{KS}$ group } & NS & $\mathrm{NaOH}+$ soil & $5,10,12.5,15$ & $7,14,28$ \\
\hline & $\mathrm{KS}$ & $\mathrm{KOH}+$ soil & $5,10,12.5,15$ & $7,14,28$ \\
\hline \multirow[t]{8}{*}{$\mathrm{N}-\mathrm{KSP}$ group } & NSP15 & $\mathrm{NaOH}+$ soil $+15 \%$ POFA & 10 & $7,14,28$ \\
\hline & NSP20 & $\mathrm{NaOH}+$ soil $+20 \%$ POFA & $5,10,12.5,15$ & $7,14,28$ \\
\hline & NSP25 & $\mathrm{NaOH}+$ soil $+25 \%$ POFA & 10 & $7,14,28$ \\
\hline & NSP30 & $\mathrm{NaOH}+$ soil $+30 \%$ POFA & 10 & $7,14,28$ \\
\hline & KSP15 & $\mathrm{KOH}+$ soil + 15\% POFA & 10 & $7,14,28$ \\
\hline & KSP20 & $\mathrm{KOH}+$ soil $+20 \%$ POFA & $5,10,12.5,15$ & $7,14,28$ \\
\hline & KSP25 & $\mathrm{KOH}+$ soil $+25 \%$ POFA & 10 & $7,14,28$ \\
\hline & KSP30 & $\mathrm{KOH}+$ soil $+30 \%$ POFA & 10 & $7,14,28$ \\
\hline \multirow[t]{6}{*}{ Heating group (Heating 1 hour) } & NSP15 & $\mathrm{NaOH}+$ soil $+15 \%$ POFA & 10 & 28 \\
\hline & NSP20 & $\mathrm{NaOH}+$ soil $+20 \%$ POFA & 10 & 28 \\
\hline & NSP25 & $\mathrm{NaOH}+$ soil $+25 \%$ POFA & 10 & 28 \\
\hline & KSP15 & $\mathrm{KOH}+$ soil $+15 \%$ POFA & 10 & 28 \\
\hline & KSP20 & $\mathrm{KOH}+$ soil $+20 \%$ POFA & 10 & 28 \\
\hline & KSP25 & $\mathrm{KOH}+$ soil $+25 \%$ POFA & 10 & 28 \\
\hline
\end{tabular}

\section{Preparation of Physical Model}

A scaled model of the ground was prepared in a rigid rectangular box attached to a steel loading frame that was built specifically for the plane-stress condition. The steel box had a dimension of $800 \mathrm{~mm} \times 380 \mathrm{~mm}$ in area and $320 \mathrm{~mm}$ in depth (Fig. 1). One side of the box had a removable $20 \mathrm{~mm}$ thick rigid Perspex panel to provide real-time monitoring of the deformation of the model soil ground during the tests. The size of the rigid box was large enough to fit the columns, and no interference developed between the walls of the box and the failure zone of the columns.

To prepare the scaled model of the ground, native soil (clay with high plasticity) was first air-dried under laboratory conditions. While waiting for the soil to air-dry, water was carefully poured into a mixing drum. Subsequently, the air-dried soil was carefully added and allowed to submerge underwater before starting to mix to avoid the spreading of dust. At just over two times the liquid limit $(120 \%)$, the slurry was made up to produce a homogeneous sample as suggested by Kitazume [32] and Bouassida and Porbaha [33]. The slurry was mixed for $10 \mathrm{~min}$ and then placed inside the steel box in three equal layers.

After creating the scaled model of the ground, in the first stage, a rigid rectangular steel plate with a diameter of $410 \mathrm{~mm}$ in width, $790 \mathrm{~mm}$ in length, and $20 \mathrm{~mm}$ in thickness, was utilized for consolidation. In the following stages, vertical stress was applied from 2 to $12.5 \mathrm{kPa}$ by hydraulic jack.
After the consolidation procedure, treated columns were prepared and installed in a group column-type arrangement using the most effective percentages of precursor (POFA) and alkaline activators concentration obtained from the UCS tests.

The diameter and length of the treated columns were decided by considering the geometry of soil-stabilizer columns in practice. In practice, the diameter of single soilcement columns typically ranges from 0.5 to $0.8 \mathrm{~m}$ and the length is between 10 and $30 \mathrm{~m}$ [34]. By considering the length and the diameter of the soil-stabilizer columns as 15 and $1.76 \mathrm{~m}$ respectively, the height of the column and the diameter of the column were designed conveniently to be $200 \mathrm{~mm}$ and $23 \mathrm{~mm}$.

Several attempts were made to install in situ columns. In the first trial, stabilized soil slurry with moisture content of $120 \%$ was poured into pre-augered holes formed in the consolidated clay. This was then cured for 12 days. It was found that a region of clay with high moisture content was created around the improvement clay area which resulting in inaccurate measurements of soil settlement during the test.

Another trial was conducted with the moisture content decreased to half (around 60\%). This procedure was similar to that conducted by Chan [35]. The column was installed by compacted it in a pre-drilled hole using a small hammer. It was observed that the column was subject to breakage and after dissecting the model, it contained high volume of air void. 
Fig. 1 Schematic of experimental setup

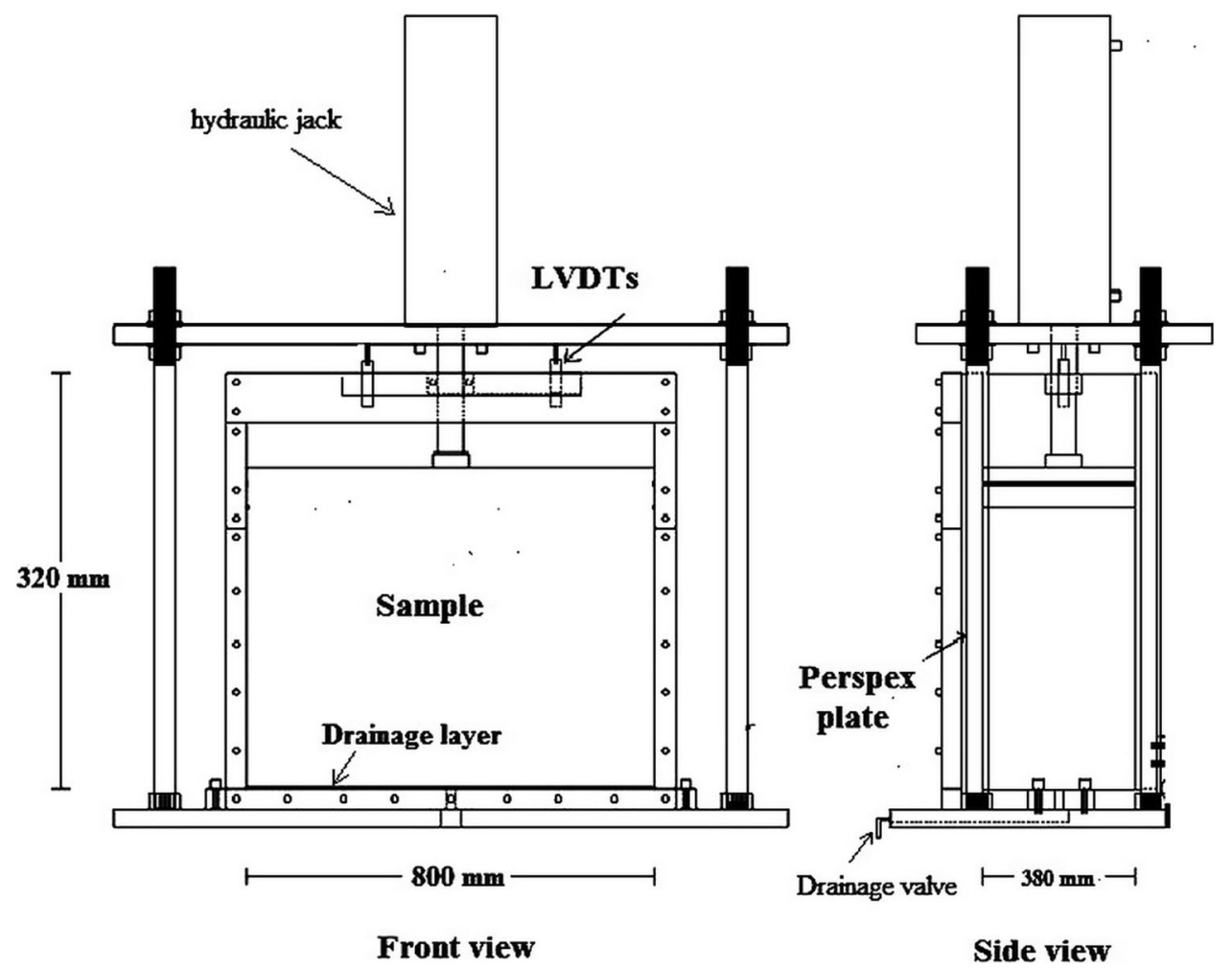

Thus it was decided to install pre-cast group of treated columns in predrilled holes and to re-consolidate the soil after this operation was completed. This procedure is similar to that described by Kitazume [32] and Bouassida and Porbaha [33]. In this procedure, columns were prepared by pouring and compacting of soil in three equal layers inside a thin-wall steel mould having a constant diameter of $23 \mathrm{~mm}$ and a length of $200 \mathrm{~mm}$.

To prepare the columns, in the first step, the dry native soil and POFA (the most effective percentage obtained in UCS tests) were mixed by hand. Meanwhile, alkaline activators were dissolved in the solution at a predetermined concentration (the most effective concentration). Subsequently, the cooled alkaline solution and extra distilled water were added into the mixture and mixed thoroughly until a uniform blend was produced.

The compaction was conducted manually using a $22 \mathrm{~mm}$-diameter steel rod to eliminate air pockets, so as to improve the homogeneity of the specimens. Note that because of the difficulty in predicting the density of the constructed stabilized soil columns, the value of the dry unit weight to be used in compaction process assumes a significant importance.

A possible option was to adopt the values obtained in the Proctor compaction test. This test is particularly adequate for measuring compaction parameters in geotechnical application projects, in which the compaction energy used is similar to the compaction energy used in the field. However, no compaction energy is involved in the mixing procedures for the construction of columns, it seemed reasonable to assume that the density of the prefabricated stabilized columns is lower than the density of the Proctor samples. As such, the dry unit weight established for all the stabilized soil columns were $10 \%$ lower than that of the Proctor test value for natural soil $\left(12.65 \mathrm{kN} / \mathrm{m}^{3}\right.$ for natural soil). The water content was also reduced to values between 29 and 30\% (relatively to the desired Proctor value). Note that the water content included both the water in the mixed alkali activator and the extra water added to the mixture to achieve the desired value.

\section{Model Design}

Three thin aluminium guiding plates were made, and each steel plate had different numbers of circular holes with a diameter of $23 \mathrm{~mm}$ spaced equally to give a specific replacement area ratio. Figure 2 illustrates the aluminium guiding plates, the number and distribution of holes in each plate, and the corresponding replacement area ratio.

Practically, a range of 10-30\% for replacement area ratio was proposed for common treatments [10]. Hence, in this study, the utilized guiding plates have a number of holes of 10,12, and 16, which are corresponding to replacement area ratios of $9.9,11.9$, and $15.82 \%$ respectively. 
Fig. 2 The aluminium guiding plates used to arrange and align the treated soil columns

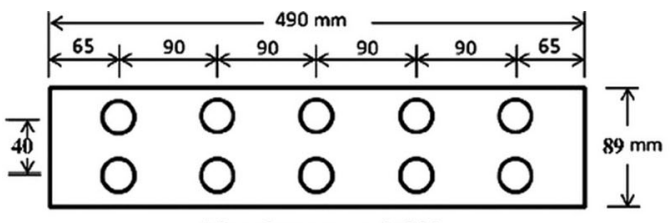

10 columns $\alpha=9.9 \%$

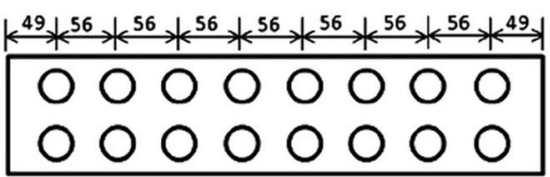

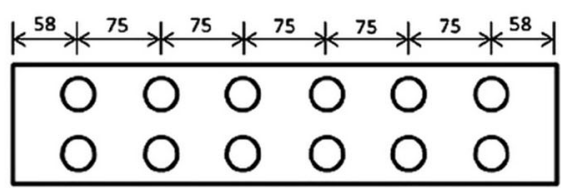

12 columns $\alpha=11.9 \%$

Column diameter $: 23 \mathrm{~mm}$

Thickness of aluminium plates : $10 \mathrm{~mm}$

16 columns $\alpha=15.82 \%$

After the aluminium guideline plate was placed at the centreline and above the model ground, a smooth steel pipe, which acts as an extruder with an inner diameter of $23 \mathrm{~mm}$ and an outer diameter of $28 \mathrm{~mm}$ (Fig. 3), was pushed vertically into each hole at predetermined locations identified by the thin aluminium guiding plates. Then, the inner soil was taken out. In the next stage, the cylindrical stabilized soil columns inserted inside the holes and in the thin aluminium plate were carefully removed (Fig. 4).

In the process of inserting the columns, a small gap may exist between the column and the surrounding soil. In this situation, a slim plastic pipe with a diameter of approximately $3 \mathrm{~mm}$ was extended to the bottom of the columnsoil gap. Thereafter, the gap was filled with diluted soil slurry (with moisture content of around 120\%) using a medical injector that was connected to the slim pipe.

In the loading stage, a mattress of sand with an average particle size of $160 \mu \mathrm{m}$ and thickness of $15 \mathrm{~mm}$ was first laid on top of the scaled ground overlaid by a square rigid aluminium plate of $420 \mathrm{~mm}$ in length, $100 \mathrm{~mm}$ in width, and $15 \mathrm{~mm}$ in thickness. This aluminium plate modelled the behaviour of a strip footing on the improved ground (Fig. 4).

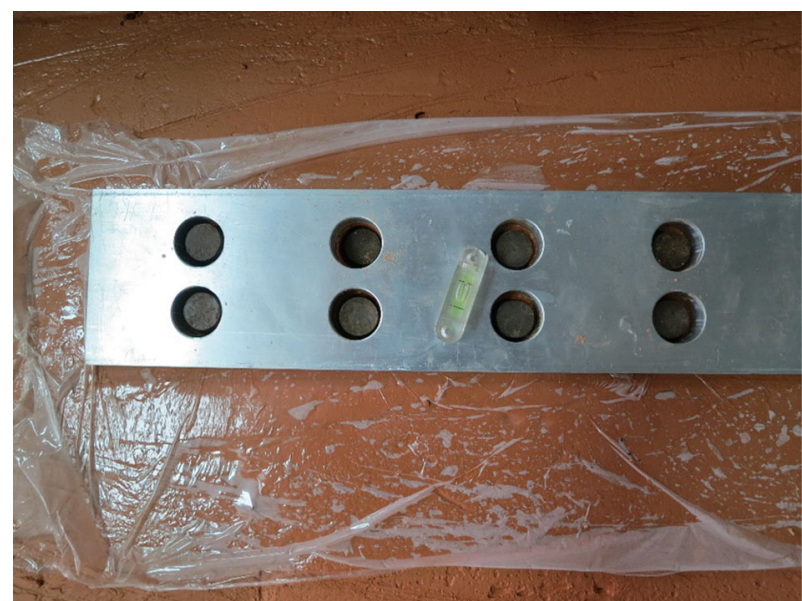

Fig. 4 Columns installation

The loading procedure was conducted using a hydraulic jack under the stress control condition with an increment of $5 \mathrm{kPa}$ per minute, and the procedure continued until it reached a normalized vertical displacement of nearly $20 \%$, at which small increments in the applied load result in relatively big increase in the settlement, which indicates that the soil has reached the failure condition (Fig. 5).
Fig. 3 Parts of extruder extension
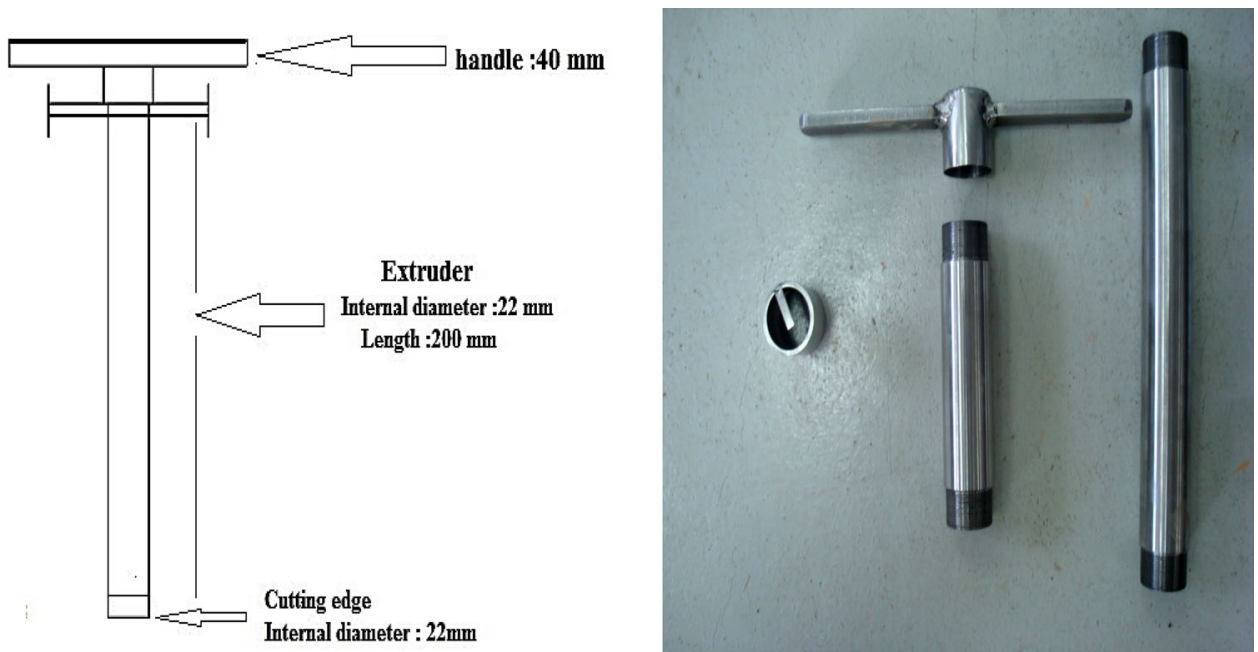


\section{Measurement of Bearing Capacity}

The ultimate bearing capacity $\left(q_{\mathrm{ult}}\right)$ was determined on the basis of the classical double tangent method. The $q_{\text {ult }}$ was obtained at the intersection of two tangents, one at the beginning and the other at the point of the plot when three successive equal incremental loads resulted in increasing incremental settlement in the log-log plot (vertical stress against displacement graphs). To eliminate the scale effect, the vertical displacement of the footing was normalized by the width of the footing. This procedure followed those of Kitazume [32] and Bouassida and Porbaha [33] which presented physical modelling tests for $q_{\text {ult }}$ analysis of cement-treated columns.

\section{Results and Discussion}

\section{Strength Development}

In this stage, the influence of factors including the use of precursor, curing condition, and type and quantity of alkaline activator on the strengthening performance of soil is evaluated.

\section{Effect of Alkaline Activator Concentration on Strength Performance}

Based on the UCS test results, irrespective of alkaline activator type, the strength development in NSP20 and KSP20 increased with the increase in quantity of both alkaline activators to a certain extent but reversed in the presence of excess activators. As shown in Figs. 6 and 7, at $5 \mathrm{M}$ alkaline activators, the dissolution of $\mathrm{Si}$ and $\mathrm{Al}$ presence in POFA was low due to relatively low base condition

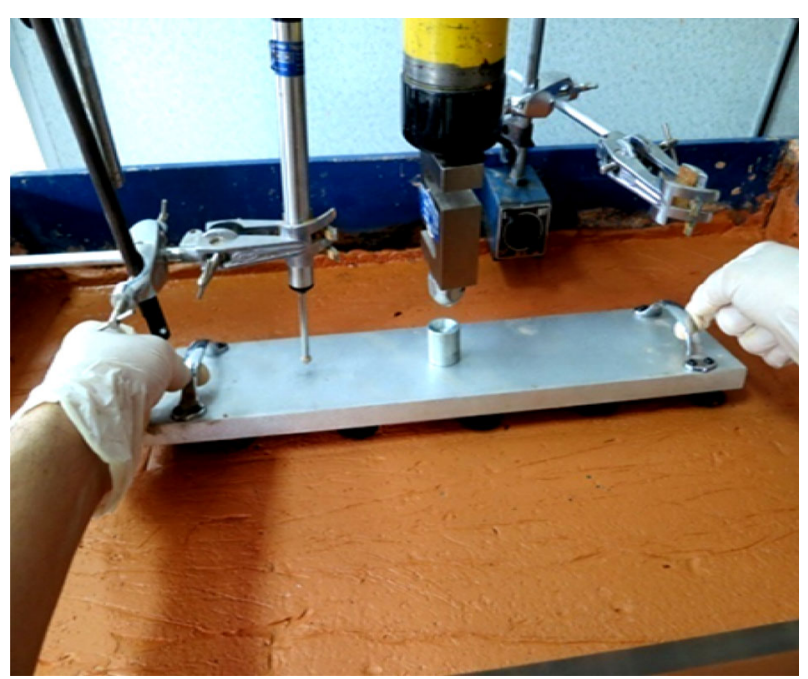

Fig. 5 Loading procedure and as expected, insufficient strength behaviour achieved by poor reactivity of alkaline activators.

For 10 and $12.5 \mathrm{M}$ alkaline activators, the base condition was higher, easily moulded and the UCS values, therefore, increased significantly. This correlates with the finding of Lee and Van Deventer [36] that when alkaline activator solutions of sufficient molarities were utilized, dissolution was greatly enhanced followed by a gel-phase framework.

However, $15 \mathrm{M}$ and higher activators concentration found not to be viable because the viscosity of the solution and thereby plasticity of parent soil increased substantially and thus, led to semi-plastic mixture and the poor UCS results. In view of these results, although the 10 and 12.5 M results exhibit virtually similar strengths, use of moderate $10 \mathrm{M} \mathrm{NaOH}$ and $10 \mathrm{M} \mathrm{KOH}$ were found to be viable as the best concentration for strength improvement of investigated soil when economy and practicality were considered.

\section{Effect of Precursor and Curing Condition on Soil Strength Performance}

Applying alkaline activators to soil induced low strengths of 179 and $159 \mathrm{kPa}$ after 7 days curing for NS and KS respectively (Figs. 8, 9). This was expected, but it must be noted that there was a slight increase in the UCS values of soil specimens in the presence of highly alkaline solutes (N-KS group) over the testing period, which could only happen because alkaline activators were able to dissolve some of the $\mathrm{Si}$ and $\mathrm{Al}$ present in natural soil for the reactions to occur [21].

However, the increase in the development of the strength of NS and KS was not significant due to the low reactivity of $\mathrm{Si}$ and $\mathrm{Al}$ present in the host soil. In contrast, the strength increased progressively when some POFA was added to the mixture. As shown in Figs. 8 and 9, when the

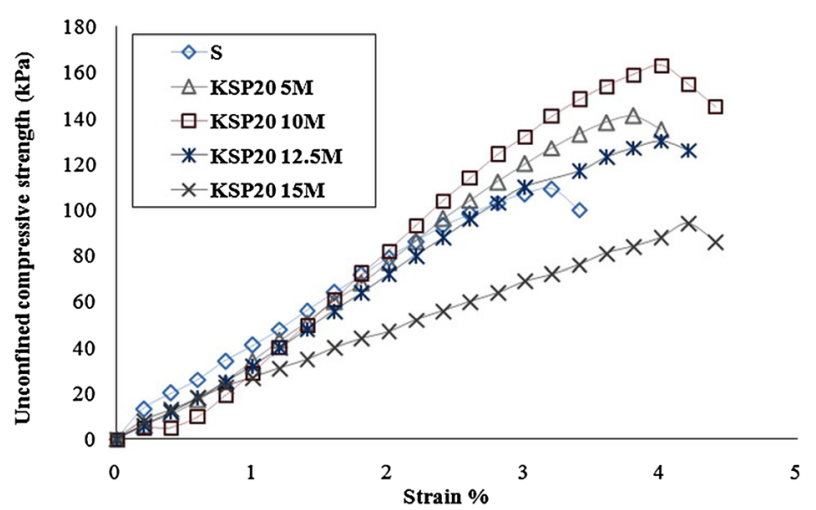

Fig. 6 Effect of potassium hydroxide concentration on soil strength development in presence of $20 \%$ POFA 


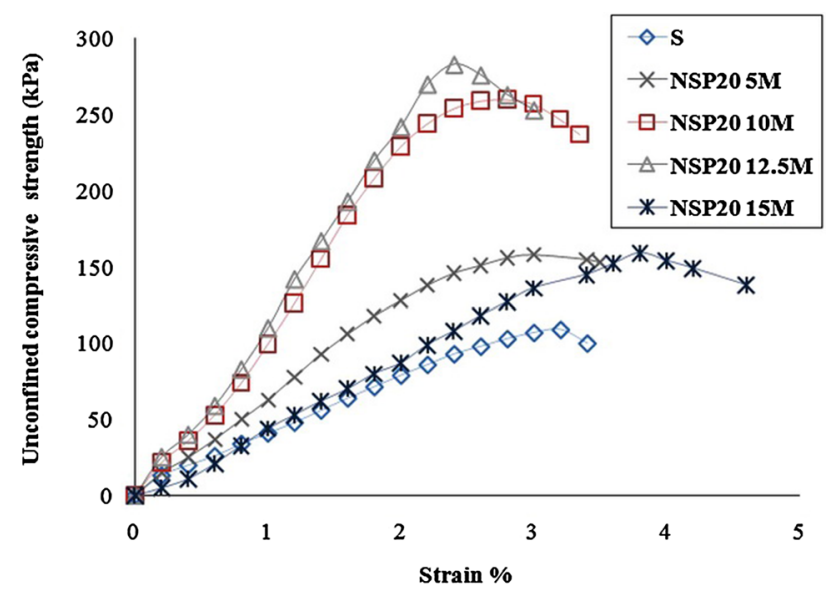

Fig. 7 Effect of sodium hydroxide concentration on soil strength development in presence of $20 \%$ POFA

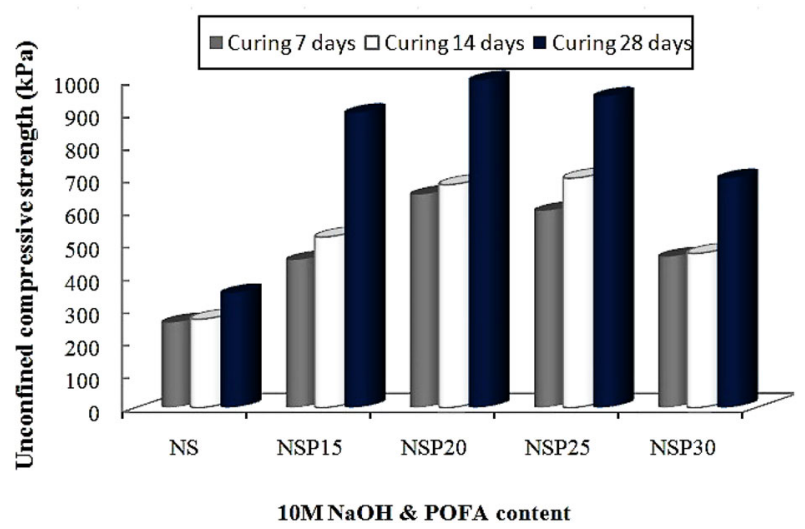

Fig. 8 Effect of precursor on soil strength development in presence of sodium hydroxide at different curing times

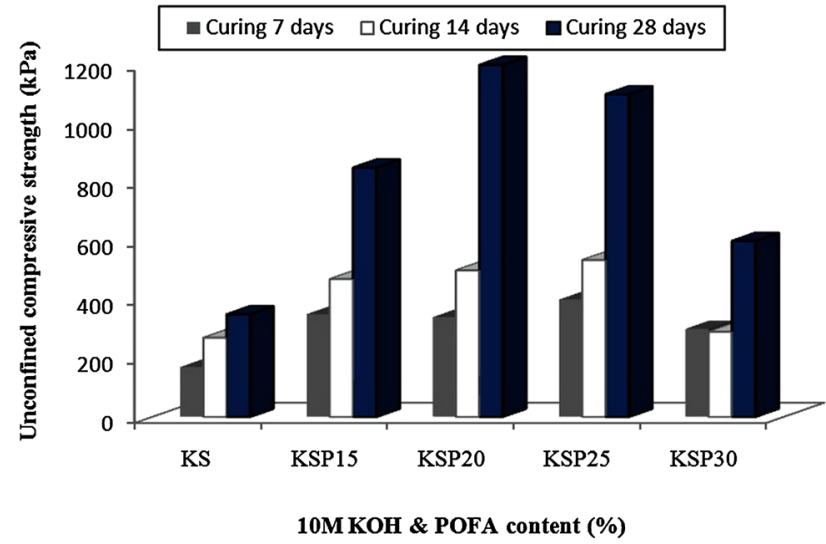

Fig. 9 Effect of precursor on soil strength development in presence of potassium hydroxide at different curing times

POFA content used in alkaline activation increases from 0 to $15 \%$, compared with NS and KS, the UCS value increases by about $226 \%$ in NSP15 and $96 \%$ in KSP15 after 7 days curing.
This assertion reflects the fact that the addition of POFA enriched the reactive $\mathrm{Si}$ and $\mathrm{Al}$ in the matrix, which allowed stronger $\mathrm{Si}-\mathrm{O}-\mathrm{Si}$ and $\mathrm{Al}-\mathrm{O}-\mathrm{Si}$ bonds to form. Therefore, utilizing POFA with highly reactive $\mathrm{Si}$ and $\mathrm{Al}$ content in the presence of alkaline solutes (N-KSP group) contributes to the much higher strength development compared to that of KS and NS (alkali-activated soil in the absence of source binder).

Besides, it is clearly seen from Figs. 8 and 9 that after low strength development of the alkali-activated samples at early age ( 7 days of curing), a higher strength gain was exhibited at a later ages (14 and 28 days of curing and higher). It is well documented that through the alkaline activation system, initial reactions are formed by the dissolution and precipitation of $\mathrm{Si}$ and $\mathrm{Al}$ present in the mixture [37, 38]. Insufficient activation time increases the quantity of unreacted source binder (POFA) within the system; it then acts as a filler in the soil mixture rather than as a binding product. Therefore, short curing times at ambient temperature lead to low to moderate strength in the treated specimens. By extension, the duration of curing time has a direct effect on the amount of activated $\mathrm{Al}$ and $\mathrm{Si}$ present in POFA that is transformed into the binding products (Figs. 8, 9). From these figures, alkali-activated samples (NSP and KSP) showed a notable increase in strength after 28 days curing at ambient temperature, regardless of the POFA content.

With regard to precursor dosage, the most effective POFA content appeared to be in the range of approximately $20-25 \%$, varying slightly with the activator type and curing time, which resulted in the formation of very dense and compacted matrix. As shown in Figs. 8 and 9, when higher percentages of POFA were incorporated (KSP30 and NSP30), the plasticity of soil increased and led to a loss in strength of the treated soil samples.

Besides the ambient curing condition, the curing temperature seems to be another means of developing higher strength in the presence of such alkaline solutions [39, 40]. As can be seen in Fig. 10, if specimens are cured at higher temperatures, particularly during the first hours of curing, the reaction rate increases even further, leading to even higher strength levels of the treated samples than that of cured at ambient temperature. Compared to N-KSP group (cured at ambient temperature), as the water content in the heating samples decreases (heating group), the activator concentration in the aqueous phase increases sharply. Increasing the activator concentration causes acceleration of the dissolution reactions, promoting the process of alkaline activation. From another angle, the sharp decrease of the sample moisture content directly favours the polycondensation and hardening process to give the final treated soil structure.

However, the practicality of applying such heating conditions on a construction site might be limited and also 


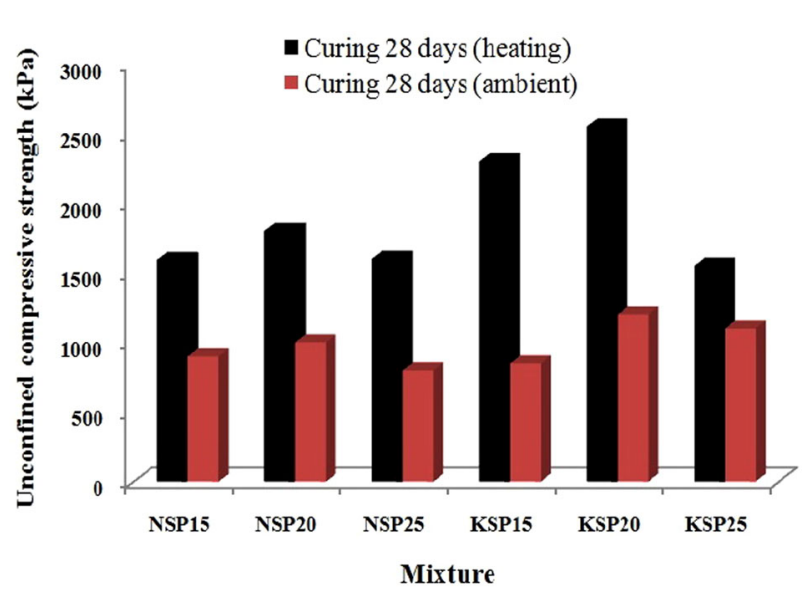

Fig. 10 Role of curing condition on soil strength development

could potentially be financially and environmentally costly, thereby defeating the aim of this study of achieving cost effectiveness and sustainability.

In terms of using different types of alkaline activators, it must be noted that the use of the Na-based activator $(\mathrm{NaOH})$ for soil stabilization is beneficial in terms of lower cost, since the price of $\mathrm{KOH}$ solution is higher than that of the $\mathrm{NaOH}$ solution. On the other hand, as shown in Figs. 8 and 9, after long curing time (28 days of curing), higher UCS values gained when the K-based activator $(\mathrm{KOH})$ was used during the alkaline activation process. This is caused by the fact that $\mathrm{K}^{+}$has a smaller hydration sphere than the other alkaline metal cation, and therefore allows more dense and intimate polycondensation reactions, which substantially increase the overall long-term strength (28 days of curing) of the treated soil [41].

\section{Bearing Capacity of the Stabilized Soil}

Seven laboratory model tests were conducted in this research to study the bearing capacity and settlement criteria of a strip foundation model loaded over stabilized soil columns, as listed in Table 4. As shown in this table, there are three series of laboratory model tests, namely $\mathrm{S}$, NSP1-3, and KSP1-3 groups under the effect of different factors. In this table, $N$ indicates the number of columns, $\alpha$ is the replacement area ratio, $\mathrm{S}$ is the native soil, NSP1-3 is the treated soil columns using $\mathrm{NaOH}$ as an activator, and $\mathrm{KSP} 1-3$ is the stabilized soil columns using $\mathrm{KOH}$ as an activator. The vertical stress-displacement/footing width curves for NSP1-3 and KSP1-3 groups are shown in Figs. 11 and 12 respectively. Furthermore, for comparison purpose, the vertical stress-displacement/footing width curve of unimproved soil ( $\mathrm{S}$ ) is shown in these figures. Note that the bearing capacity and settlement were measured two times for each test group (NSP1-3 and KSP1-3).

\section{Untreated Case}

It can be seen in Figs. 11 and 12 that the vertical load in untreated ground (S) increases rapidly with the increase of settlement at first and reaches a plateau at about 0.09 of displacement/footing width. The stress corresponding to the plateau was taken as the $q_{\text {ult }}$ of the footing. Also, as shown in this figure, the vertical stress-displacement/footing width curve of untreated soil possessed the ductile behaviour.

It is noted that the average UCS values for the natural clayey soil (S) was $11.6 \mathrm{kPa}$, and $12.8 \mathrm{kPa}$ for the top, and bottom positions of model ground respectively. Also, the native soil in the physical model test was in a nearly undrained condition since the drainage valves were closed during the loading procedure. With respect, undrained shear strength of equal to zero was adopted for natural soil. Therefore, $C_{\text {us }}$ of the natural soil was between 5.8 and $6.4 \mathrm{kPa}$.

\section{Treated Cases}

It can be clearly seen in Figs. 11 and 12 that increasing the replacement area ratio, $\alpha$, results in more improvement in the $q_{\mathrm{ult}}$ of treated columns (N-KSP1-3), irrespective to the alkali activator type. Other than that, as shown in these figures, compared to untreated soil (S), the $q_{\text {ult }}$ increased sharply in treated cases (N-KSP1-3). This behaviour is believed to have been due to the use of alkaline activation process in treated cases (N-KSP1-3). In this respect, compared to unimproved soil (S), in the case of NSP1-3, the $q_{\text {ult }}$ of the model ground at replacement area ratio of $9.9,11.9$, and $15.82 \%$ increased up to 87,125 , and $175 \%$ respectively. An even higher enhancement was achieved in the case of the KSP3, for which higher increased values of bearing capacities up to $192 \%$ was observed at replacement area ratio of $15.82 \%$.

The mechanism of reaction in treated cases (N-KSP1-3) is driven by the ability of highly alkaline solutes, including either $\mathrm{NaOH}$ or $\mathrm{KOH}$, to dissolve amorphous silica and alumina source materials (mainly from POFA and possibly from the colloidal fraction of soil) into the matrix. In such a condition, a poly-condensation process (a reaction that chemically integrates minerals through alkaline activation) occurs to form a three-dimensional structure [42-44]. The formation of this new structure is responsible for the high $q_{\mathrm{ult}}$ values in all treated soil columns (N-KSP1-3).

From Figs. 11 and 12, in treated cases (N-KSP1-3), the vertical stress increased rapidly at first, and then the model ground exhibited progressive softening since the bearing pressure decrease gradually after the peak. Similar laboratory observations in the case of cemented columns were reported by several other researchers [32, 45]. 
Table 4 Mixture proportions of various series of test specimens

\begin{tabular}{lllll}
\hline Group series & Test no. & Samples & $N$ & $\alpha$ \\
\hline \multirow{3}{*}{ NSP1-3 group } & S & Natural soil & - & - \\
& NSP1 & $10 \mathrm{M} \mathrm{NaOH}+$ soil + 20\% POFA & 10 & 9.9 \\
& NSP2 & $10 \mathrm{M} \mathrm{NaOH}+$ soil $+20 \%$ POFA & 12 & 11.9 \\
KSP1-3 group & NSP3 & $10 \mathrm{M} \mathrm{NaOH}+$ soil $+20 \%$ POFA & 16 & 15.82 \\
& KSP1 & $10 \mathrm{M} \mathrm{KOH}+$ soil $+20 \%$ POFA & 10 & 9.9 \\
& KSP2 & $10 \mathrm{M} \mathrm{KOH}+$ soil $+20 \%$ POFA & 12 & 11.9 \\
& KSP3 & $10 \mathrm{M} \mathrm{KOH}+$ soil $+20 \%$ POFA & 16 & 15.82 \\
\hline
\end{tabular}

$N$ and $\alpha$ designate number of columns and replacement area ratio respectively

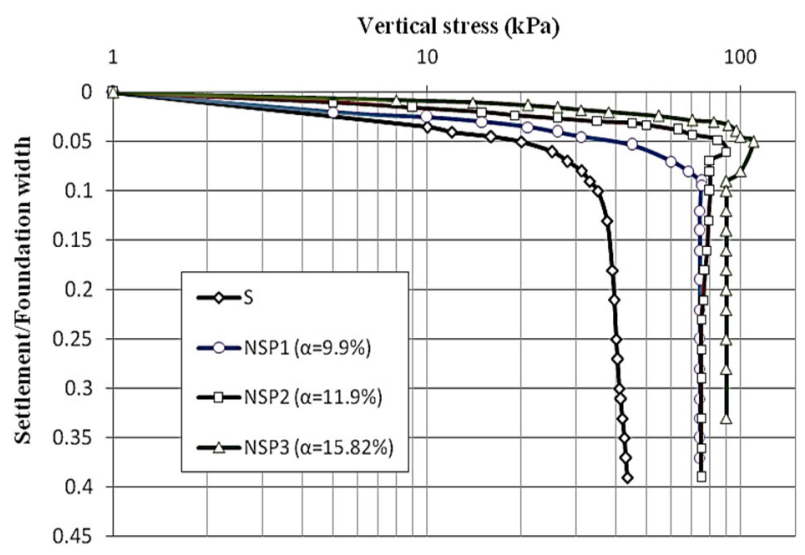

Fig. 11 The relationship between vertical stress and displacement in NSP1-3 group

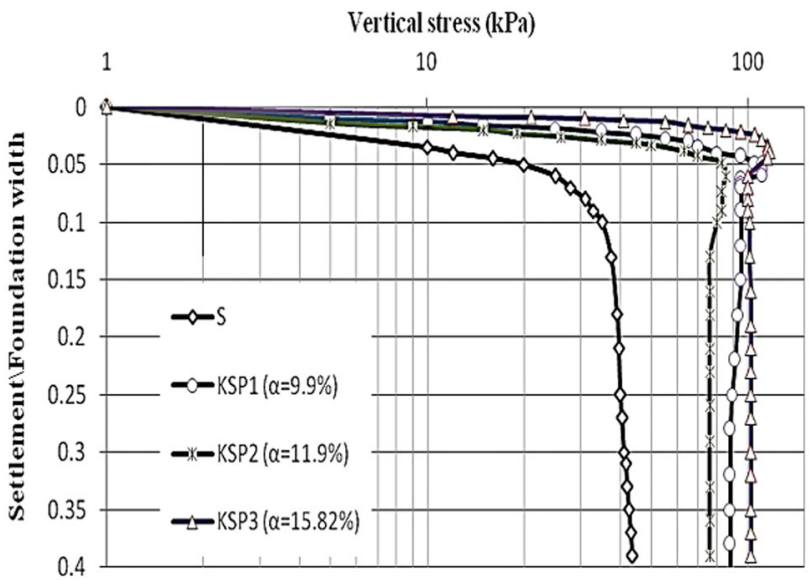

Fig. 12 The relationship between vertical stress and displacement in KSP1-3 group

As shown in Figs. 11 and 12, the slope of the stress normalized displacement graphs in the case of KSP1-3 was higher compared to NSP1-3, which showed failure at lower displacements. This is caused by the fact that $\mathrm{K}^{+}$has a larger size than the other alkaline metal cation $\left(\mathrm{Na}^{+}\right)$, and therefore allows more dense and intimate polycondensation reactions, which substantially increase the strength and stiffness of the treated columns (KSP1-3). With respect, it can be concluded that the size and charge density of the alkaline activator play significant roles in controlling the rate and extent of the activation process in treated columns during a loading procedure.

\section{Conclusions}

Based on the laboratory and physical model tests presented in this paper, the following conclusions were reached.

- Through alkaline activation process, the addition of POFA (precursor) enriched the reactive $\mathrm{Si}$ and $\mathrm{Al}$ in the soil matrix, which allowed stronger Si-O-Si and Al$\mathrm{O}-\mathrm{Si}$ bonds to form. In this respect, the highest compressive strength value of $1200 \mathrm{kPa}$ after 28 days curing was recorded for the KSP mixture, which was $242 \%$ higher than that obtained for the similar mixture without precursor (KS group). With regard to precursor dosage, the most effective POFA content appeared to be in the range of approximately $20-25 \%$, varying slightly with the activator type and curing time.

- Curing time was shown to have a significant strengthening effect on the treated soil. For the NSP and KSP mixtures, and after 28 days of curing, UCS values of 990 and $1200 \mathrm{kPa}$ were observed, respectively. The results revealed that the duration of curing has a direct effect on the amount of activated reactants transformed into the binding products.

- Heating process has significant effect on soil strength development during alkaline activation. The UCS of the KSP20 mixture reached value of $2550 \mathrm{kPa}$ at 28 days, which is $112 \%$ higher than that obtained with the similar mixture in absence of heating process. As the water content decreases during heating process, the alkaline activator concentration in the aqueous phase increases sharply. Increasing the activator concentration causes acceleration of the dissolution reactions, promoting the process of alkaline activation.

- The type and quantity of alkaline activators are crucial factors to consider in explanations of the strengthening 
effect. In terms of using alkaline activators, higher UCS values at 28 days can be observed when the K-based activator $(\mathrm{KOH})$ was used for alkali activation.

- Depending on both the replacement area ratio and the alkali-activator type, physical model test results indicated that a considerable bearing capacity increment of up to $192 \%$ of treated columns could be achieved.

Acknowledgements The authors sincerely thank the University Putra Malaysia and Ministry of Science, Technology and Innovation (MOSTI) for financial supporting this research (Escience Fund, Vot: 03-01-04-SF2011, static and dynamic behaviour of stabilized clay soil using oil palm dirty gold).

\section{References}

1. Sabih O, Shafique MJ, Hussain RR (2011) Methods of soil stabilization. CRC Press, Boca Raton

2. Kirsch K, Bell A (2012) Ground improvement. CRC Press, Boca Raton

3. Saitoh S, Suzuki Y, Shirai K (1985) Hardening of soil improved by deep mixing method. In: Proceedings of 11th international conference on soil mechanics and foundation engineering. San Francisco, pp 1745-1748

4. Fang Y, Chung Y, Yu F, Chen T (2001) Properties of soil-cement stabilised with deep mixing method. Ground Improv 5(2):69-74. doi:10.1680/grim.2001.5.2.69

5. Porbaha A (1998) State of the art in deep mixing technology. Part I: Basic concepts and overview. Ground Improv 2(2):81-92. doi:10.1680/grim.1998.2.2.081

6. Kitazume M, Terashi M (2013) The deep mixing method. CRC Press, Leiden

7. Pourakbar S (2015) Deep mixing columns. Pertanika J Sch Res Rev 1(1):8-17

8. Fasihnikoutalab MH, Asadi A, Huat BK, Ball RJ, Pourakbar S, Singh P (2016) Utilisation of carbonating olivine for sustainable soil stabilisation. Environ Geotech. doi:10.1680/jenge.15.00018

9. Kitazume M (2002) The deep mixing method—principle, design and construction. Balkema Press, Tokyo

10. Bruce DA (2001) Practitioner's guide to the deep mixing method. Proc ICE-Ground Improv 5(3):95-100. doi:10.1680/grim.2001.5. 3.95

11. Prusinski JR, Bhattacharja S (1999) Effectiveness of Portland cement and lime in stabilizing clay soils. Transp Res Rec 1652(1):215-227

12. Saitoh S (1988) Experimental study of engineering properties of cement improved ground by the deep mixing method. Ph.D. thesis, Nihon University

13. Weng L, Sagoe-Crentsil K (2007) Dissolution processes, hydrolysis and condensation reactions during geopolymer synthesis: Part I-Low Si/Al ratio systems. J Mater Sci 42(9): 2997-3006. doi:10.1007/s10853-006-0820-2

14. Yunsheng Z, Wei S, Zongjin L, Xiangming Z, Chungkong C (2008) Impact properties of geopolymer based extrudates incorporated with fly ash and PVA short fiber. Constr Build Mater 22(3):370-383. doi:10.1016/j.conbuildmat.2006.08.006

15. Harichane K, Ghrici M, Kenai S, Grine K (2011) Use of natural pozzolana and lime for stabilization of cohesive soils. Geotech Geol Eng 29(5):759-769. doi:10.1007/s10706-011-9415-Z

16. Basha E, Hashim R, Mahmud H, Muntohar A (2005) Stabilization of residual soil with rice husk ash and cement. Constr Build Mater 19(6):448-453. doi:10.1016/j.conbuildmat.2004.08.001
17. Duxson P, Fernández-Jiménez A, Provis JL, Lukey GC, Palomo A, Van Deventer J (2007) Geopolymer technology: the current state of the art. J Mater Sci 42(9):2917-2933

18. Davidovits J (1991) Geopolymers. J Therm Anal Calorim 37(8):1633-1656

19. Zhang M, Guo H, El-Korchi T, Zhang G, Tao M (2013) Experimental feasibility study of geopolymer as the next-generation soil stabilizer. Constr Build Mater 47:1468-1478. doi:10.1016/j. conbuildmat.2011.12.007

20. Zhang M, Zhao M, Zhang G, Nowak P, Coen A, Tao M (2015) Calcium-free geopolymer as a stabilizer for sulfate-rich soils. Appl Clay Sci 108:199-207. doi:10.1007/s12205-013-1638-5

21. Cristelo N, Glendinning S, Pinto AT (2011) Deep soft soil improvement by alkaline activation. Proc ICE-Ground Improv 164(2):73-82. doi:10.1680/grim.900032

22. Cristelo N, Glendinning S, Fernandes L, Pinto AT (2013) Effects of alkaline-activated fly ash and Portland cement on soft soil stabilisation. Acta Geotech 8(4):395-405. doi:10.1007/s11440012-0200-9

23. Cristelo N, Miranda T, Oliveira DV, Rosa I, Soares E, Coelho P, Fernandes L (2015) Assessing the production of jet mix columns using alkali activated waste based on mechanical and financial performance and $\mathrm{CO}_{2}$ (eq) emissions. J Clean Prod. doi:10.1016/ j.jclepro.2015.04.102

24. Singhi B, Laskar AI, Ahmed MA (2015) Investigation on soilgeopolymer with slag, fly ash and their blending. Arab J Sci Eng. doi:10.1007/s13369-015-1677-y

25. D2487 A (2010) Standard practice for classification of soils for engineering purposes (unified soil classification system). ASTM

26. Johari M, Zeyad A, Muhamad Bunnori N, Ariffin K (2012) Engineering and transport properties of high-strength green concrete containing high volume of ultrafine palm oil fuel ash. Constr Build Mater 30:281-288. doi:10.1016/j.conbuildmat. 2011.12.007

27. Yusuf MO, Johari MAM, Ahmad ZA, Maslehuddin M (2014) Shrinkage and strength of alkaline activated ground steel slag/ ultrafine palm fuel ash pastes and mortars. Mater Des. doi:10. 1016/j.matdes.2014.06.062

28. Yusuf MO, Megat Johari MA, Ahmad ZA, Maslehuddin M (2014) Evolution of alkaline activated ground blast furnace slagultrafine palm oil fuel ash based concrete. Mater Des 55:387-393. doi:10.1016/j.matdes.2013.09.047

29. Mijarsh M, Johari M, Ahmad Z (2014) Synthesis of geopolymer from large amounts of treated palm oil fuel ash: application of the Taguchi method in investigating the main parameters affecting compressive strength. Constr Build Mater 52:473-481. doi:10. 1016/j.conbuildmat.2013.11.039

30. Pourakbar S, Asadi A, Huat BB, Fasihnikoutalab MH (2015) Stabilization of clayey soil using ultrafine palm oil fuel ash (POFA) and cement. Transp Geotech 3:24-35. doi:10.1016/j. trgeo.2015.01.002

31. Standard B 1377 (1990) Methods of test for soils and civil engineering purposes. British Standards Institution, London

32. Kitazume M (1996) Bearing capacity of improved ground with column type DMM. In: Proceeding of the 2nd international conference on ground improvement geosystems, vol 3. Tokyo, pp 503-508

33. Bouassida M, Porbaha A (2004) Ultimate bearing capacity of soft clays reinforced by a group of columns-application to a deep mixing technique. Soils Found 44(3):91-101

34. Goda Y (2002) Research group of marine observation data analysis and application, coastal wave observation, coastal development institute of technology. KORDI Press, Seoul. doi:10.1016/j.cemconres.2009.10.017

35. Chan CM (2006) A laboratory investigation of shear wave velocity in stabilised soft soils. University of Sheffield 
36. Lee W, Van Deventer J (2002) Structural reorganisation of class F fly ash in alkaline silicate solutions. Colloids Surf A 211(1): 49-66. doi:10.1016/S0927-7757(02)00237-6

37. Davidovits J (2005) Geopolymer chemistry and sustainable development. The poly (sialate) terminology: a very useful and simple model for the promotion and understanding of greenchemistry. In: Proceedings of 2005 geopolymer conference. pp 9-15

38. Pourakbar S, Huat BK (2016) A review of alternatives traditional cementitious binders for engineering improvement of soils. Int $\mathbf{J}$ Geotech Eng. doi:10.1080/19386362.2016.1207042

39. Kong DL, Sanjayan JG (2010) Effect of elevated temperatures on geopolymer paste, mortar and concrete. Cem Concr Res 40(2):334339. doi:10.1016/j.cemconres.2009.10.017

40. Pan Z, Sanjayan JG (2010) Stress-strain behaviour and abrupt loss of stiffness of geopolymer at elevated temperatures. Cem Concr Compos 32(9):657-664. doi:10.1016/j.cemconcomp.2010. 07.010
41. Pourakbar S, Asadi A, Huat BB, Fasihnikoutalab MH (2015) Soil stabilization with alkali-activated agro-waste. Environ Geotech 2(6):359-370

42. Xu H, Van Deventer J (2000) The geopolymerisation of aluminosilicate minerals. Int J Miner Process 59(3):247-266. doi:10. 1016/S0301-7516(99)00074-5

43. Van Deventer J, Provis J, Duxson P, Lukey G (2007) Reaction mechanisms in the geopolymeric conversion of inorganic waste to useful products. J Hazard Mater 139(3):506-513. doi:10.1016/ j.jhazmat.2006.02.044

44. Ranjbar N, Mehrali M, Behnia A, Alengaram UJ, Jumaat MZ (2014) Compressive strength and microstructural analysis of fly ash/palm oil fuel ash based geopolymer mortar. Mater Des 59:532-539. doi:10.1016/j.matdes.2014.03.037

45. Yin JH, Fang Z (2010) Physical modeling of a footing on soft soil ground with deep cement mixed soil columns under vertical loading. Mar Georesour Geotechnol 28(2):173-188. doi:10.1080/ 10641191003780872 